\title{
Hydrological links between cosmic-ray soil moisture retrievals and remotely sensed evapotranspiration across a semi-arid pasture site
}

\author{
$\underline{\text { R. B. Jana }}^{a}$, A. Ershadi ${ }^{a}$ and M. F. McCabe ${ }^{a}$ \\ ${ }^{a}$ Water Desalination and Reuse Center, King Abdullah University of Science and Technology, \\ Thuwal, Kingdom of Saudi Arabia \\ Email: Raghavendra.Jana@kaust.edu.sa
}

\begin{abstract}
Soil moisture and land surface evaporation, which includes soil evaporation, canopy interception and transpiration processes, are key factors affecting water cycle behavior and feedbacks between the land surface and the atmosphere at a range of scales. Measurement of soil moisture at intermediate resolutions is a challenge that has been addressed to a certain extent by the Cosmic Ray Soil Moisture Observing System (COSMOS). We present here a study to examine the link between the COSMOS soil moisture retrievals and evapotranspiration (ET) estimates obtained from remote sensing at a semi-arid pasture site near Baldry, in the central-west of New South Wales, Australia. COSMOS soil moisture was compared to ET estimates obtained by applying the PT-JPL method to remote sensing products of the Moderate Resolution Imaging Spectroradiometer (MODIS) sensor. Ancillary data included air temperature, humidity, and radiation components. Use of Quartile-Quartile (Q-Q) plots and Analysis of Variance (ANOVA) with box plots provide a graphical estimate for the similarity of the distributions of the two quantities. The relationships were tested across the entire period of record, as well as across shorter periods in order to analyze local scale discrepancies. Results show that the COSMOS soil moisture, which is representative of much of the root zone of the pasture field, is well correlated with the modeled ET under most conditions. It was also noted that under high soil moisture conditions with low temperatures, the PTJPL method produced ET values inconsistent with measurements from a local eddy covariance tower, and also with the COSMOS soil moisture. This leads to further investigations regarding appropriate models for particular conditions.
\end{abstract}

Keywords: COSMOS, soil moisture, evapotranspiration 


\section{INTRODUCTION}

Soil moisture and evapotranspiration (ET) are key factors affecting water cycle behavior and feedbacks between the land surface and the atmosphere at a range of scales (Manfreda et al., 2007; Seneviratne et al., 2010). These feedbacks are not generally well-identified or understood, especially over arid regions (Wang et al., 2012). Over the years, a number of studies have sought to characterize this and related links, with one aim being to predict one variable through knowledge of the other (Mintz and Walker, 1993; Wetzel and Chang, 1987) or to use these relationships to draw inferences about related hydrological components (McCabe et al., 2005b; Stisen et al., 2011). To further this aim, remote sensing based approaches have been employed to make measurements of the various elements of the hydrological cycle, including soil moisture (Liu et al., 2012), evaporation (Su et al., 2007) and even linked processes such as vegetation response (Liu et al., 2011). Traditionally, soil moisture has been measured using either ground-based sensors or air/satellite-remote sensing techniques (McCabe et al., 2005a). Ground-based measurements tend to be at an extremely fine spatial scale of a few centimeters, while remotely sensed soil moisture has resolutions of several hundreds of meters to tens of kilometers (McCabe et al., 2005c).

Unfortunately, large scale soil moisture estimates are generally unable to capture the field-scale spatial heterogeneity (Manfreda et al., 2007). While a large number of point-scale measurements can technically be made and spatially averaged over the area of interest, in practice, it is not feasible over multiple fields. Different spatial scaling approaches have been employed for some time now to obtain soil moisture values at intermediate resolutions where no measurements are available (e.g., Jana and Mohanty, 2012a; Jana and Mohanty, 2012b; Jana et al., 2012; Jana et al., 2008). Recently, the challenge of measurement of soil moisture at intermediate resolutions has been addressed to a certain extent by the Cosmic Ray Soil Moisture Observing System (COSMOS) developed by Zreda et al. (2012). A ground-based sensor working on the principle of determining the neutron density of cosmic rays, COSMOS provides soil moisture measurements at spatial resolutions of several hundred meters in diameter, compared to the tens of kilometers available from satellite based approaches. In addition, the COSMOS's effective depth of measurement of $12-76 \mathrm{~cm}$ is much greater than those of other remote sensing techniques, which are closer to a few centimeters. The increased measurement depth indicates that the COSMOS determined soil moisture value should be more representative of much of the root zone and its dynamics (Desilets et al., 2010).

The root zone soil moisture is a critical quantity regulating both evaporation and transpiration. To some degree, transpiration depends upon the amount of water available to the plant in the root zone, while evaporation depends on the surface soil moisture. It has been shown (Wetzel and Chang, 1987) that the soil moisture can be a limiting factor in the process of evapotranspiration. It is hypothesized that with better estimates of the root-zone soil moisture, the relationship between the ET and soil moisture will be more robust. To test the validity of this hypothesis, a preliminary investigation was undertaken to assess the link between the COSMOS soil moisture retrievals and evapotranspiration estimates obtained from remote sensing.

\section{METHODS AND DATA}

The Priestley-Taylor-Jet Propulsion Laboratory (PT-JPL) model (Fisher et al., 2008) was chosen to estimate ET from remotely sensed MODIS data. The model has shown strong performance in a number of ET intercomparison studies (Ershadi et al., 2014; Vinukollu et al., 2011). The model uses both local and remote sensing data to calculate a set of constraint functions based on the contribution of (i) green canopy fraction, (ii) relative wetness of the canopy, (iii) air temperature, (iv) plant water stress and (v) soil water stress towards reducing the potential Priestley-Taylor ET to actual values. Further details of the PT-JPL model can be found in the article by Fisher et al. (2008).

The Baldry study area is a pasture site located in a semi-arid region of central-western New South Wales, Australia at latitude -32.87 degrees, longitude 148.52 degrees and having an elevation of $438 \mathrm{~m}$ above mean sea level. The site was part of the Australian National Cosmic Ray Soil Moisture Monitoring Facility (CosmOz) network, established by the Environmental Research and Monitoring Team of the Commonwealth Scientific and Research Organization (CSIRO). A COSMOS probe (Zreda et al., 2012) was installed at the site in late March 2011. Other meteorological sensors provided ancillary data, including an eddy-covariance flux tower and three Time Domain Reflectometry (TDR) moisture sensors at the soil surface. Figure 1 shows the location of the Baldry test site together with an image of the COSMOS installation. Further information on the site installations in the CosmOz network is provided by Hawdon et al. (2014). 


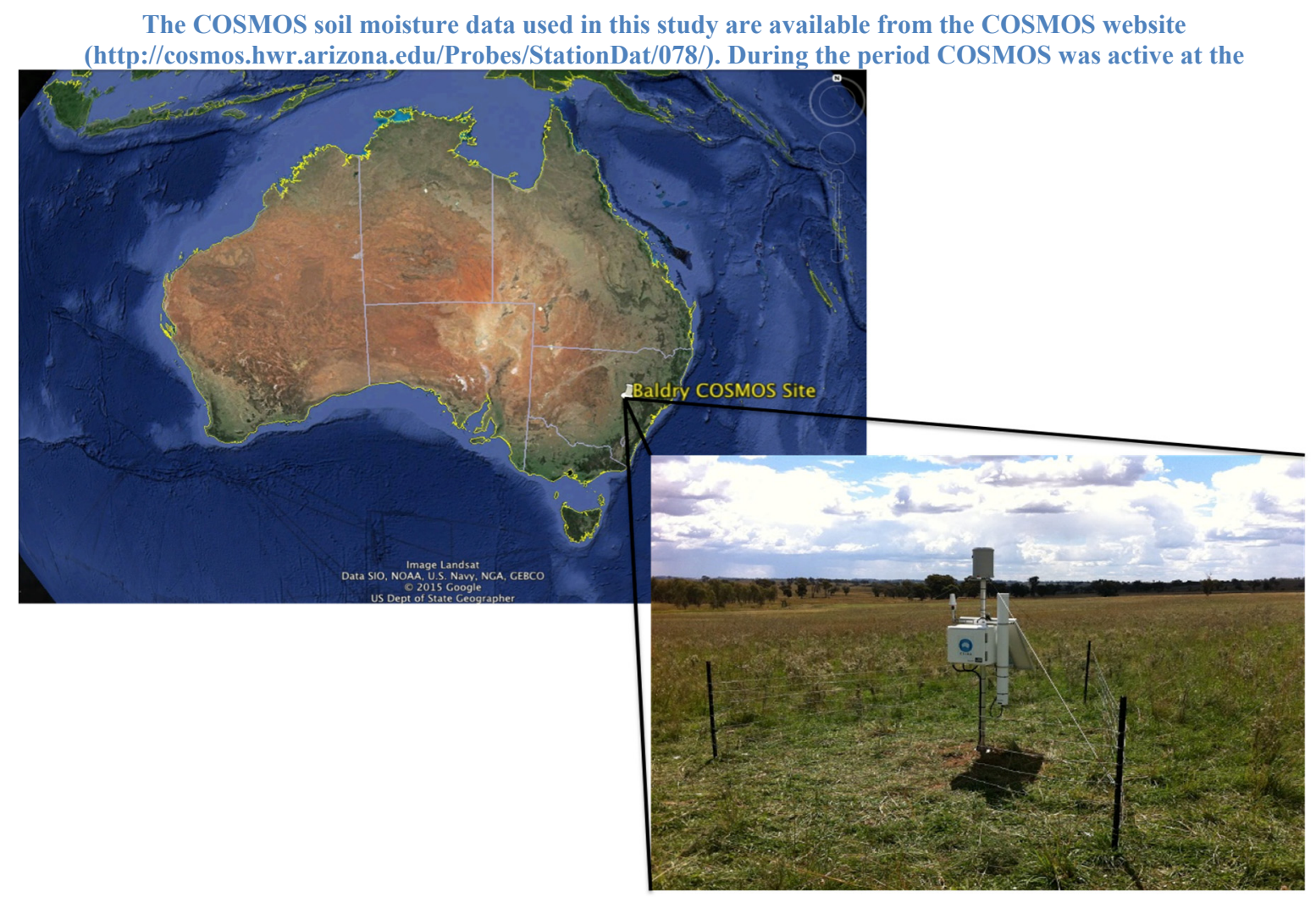

Figure 1. Location of Baldry COSMOS site, and picture of installation (photo from the COSMOS data repository).

Baldry site (30 March 2011 to 13 March 2014), accounting for gaps in the dataset and also availability of concurrent ancillary data, a total of 684 days of record (DoR) from 2011-2013 were selected for this study. The satellite-based remote sensing data used for ET modeling are mainly obtained from the ModerateResolution Imaging Spectroradiometer (MODIS) sensor products. Land surface temperature data are from daily MOD11A1 and MYD11A1 products of Terra and Aqua satellites, respectively (Wan, 2009). The Normalized Difference Vegetation Index (NDVI) data are obtained from the MOD13Q1 product (Solano et al., 2010). The meteorological forcing data such as radiation components, air temperature and humidity were obtained from the eddy-covariance tower at the site.

All ET and soil moisture data used in this study were standardized by computing the standard score, i.e.,

$$
X_{s t}=\frac{X-\bar{X}}{\sigma}
$$

where $X_{s t}$ is the standardized data point, $X$ is the raw data, $\bar{X}$ is the mean of the raw dataset, and $\sigma$ is the standard deviation of the raw dataset. This step reduces all data to units of standard deviation, and thus helps to compare different quantities as distributions.

\section{RESULTS AND DISCUSSION}

Figure 2 shows the precipitation data at the study site, overlain by the standardized soil moisture and ET data. In order to probe the link between the soil moisture and the ET, we used the non-parametric Q-Q plots and box plots.

Figure 3 shows the Q-Q plot for the COSMOS soil moisture data versus the PT-JPL derived ET data. The red line signifies the extrapolation of the slope of the inter-quartile range (highlighted in grey). A close match between the Q-Q plot (in blue) and the red line signifies that the two quantities have been sampled from the same distribution. From the plot, we see that the two quantities (soil moisture and ET) are drawn from similar distributions, especially in the inter-quartile range. This observation is further supported by the graphical output (boxplots) of the one-way ANOVA test (see Figure 4). An ANOVA test generally provides both a box plot and a table of statistics, the most relevant of which is usually the p-value. This value signifies how 
different the means of the two quantities are from each other: the higher the value, the more statistically similar the means. However, for this study, the data being compared were standardized to have zero-mean distributions in order to be able to compare different physical quantities. Hence, the p-value from an ANOVA would be 1, signifying that the two means are statistically the same. This statistic would not be useful to understand the behavior of the two distributions. Hence, the boxplot portion of the ANOVA result is preferred in this case.

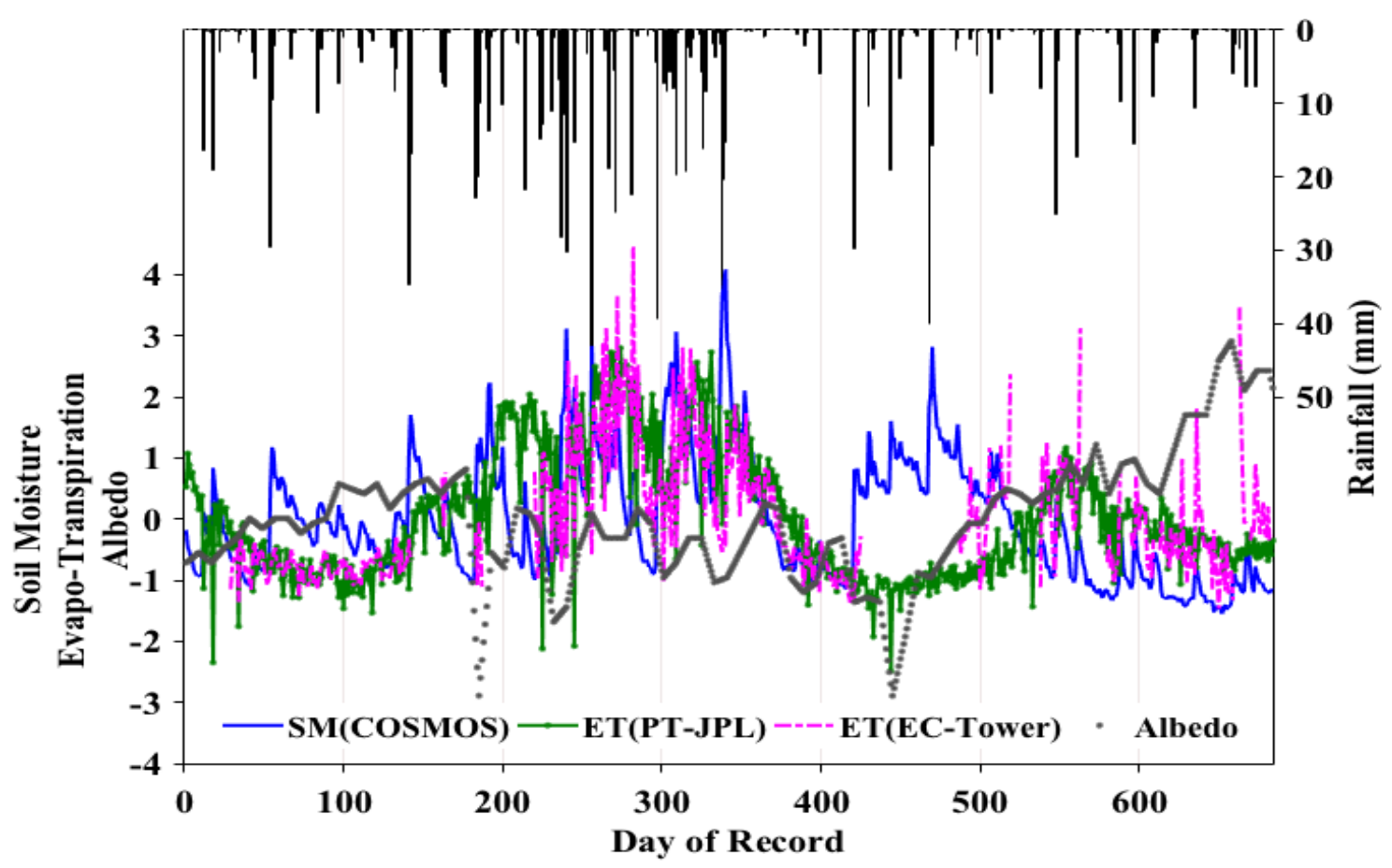

Figure 2. Standardized soil moisture and evapotranspiration data, along with precipitation, for the entire period of record.

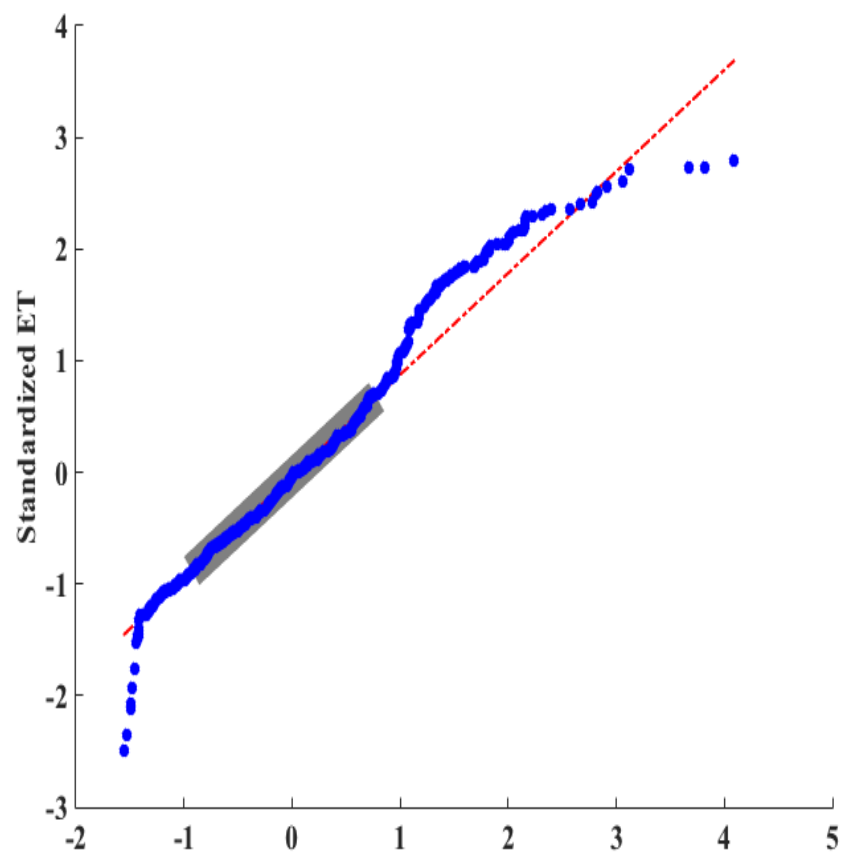

Figure 3. Q-Q plot of standardized COSMOS soil moisture (SM) versus standardized PT-JPL-derived evapotranspiration (ET).
The COSMOS soil moisture distribution appears to be slighly skewed to the left, while the ET is more equally distributed. Again, as in the Q$\mathrm{Q}$ plot, it is seen that the inter-quartile range is very similar for both quantities.

In order to better understand the dynamics between the soil moisture and ET signatures, we divided the timeline into four separate periods based on the signal trends and also the level of agreement between the two signatures. Period \#1 ran from Day of Record (DoR) 55 to DoR 144. During this period both the SM and the ET had a consistent downward trend (see Figure 2). Period \#2 runs between DoR 321 and 410 where the SM and ET signatures were seen to be behaving consistently with each other. Period \#3 runs from DoR 410 to DoR 500 where several wetting and drying cycles were observed for the soil moisture, without corresponding 
changes in the ET signature. Finally, Period \#4, between DoR 501 and 590, displays signatures that behave contrary to each other in that an increase in soil moisture corresponds to a decrease in the ET. These four time slices were chosen to better analyze the correspondence between the COSMOS soil moisture measurements and the PT-JPL derived evapotranspiration estimates under different conditions. Raw data from these shorter time periods were individually standardized using the mean and standard deviation for each particular period.

Figure 5 shows the Q-Q plots of soil moisture versus PT-JPL-derived ET estimates for the four separate periods of analysis.

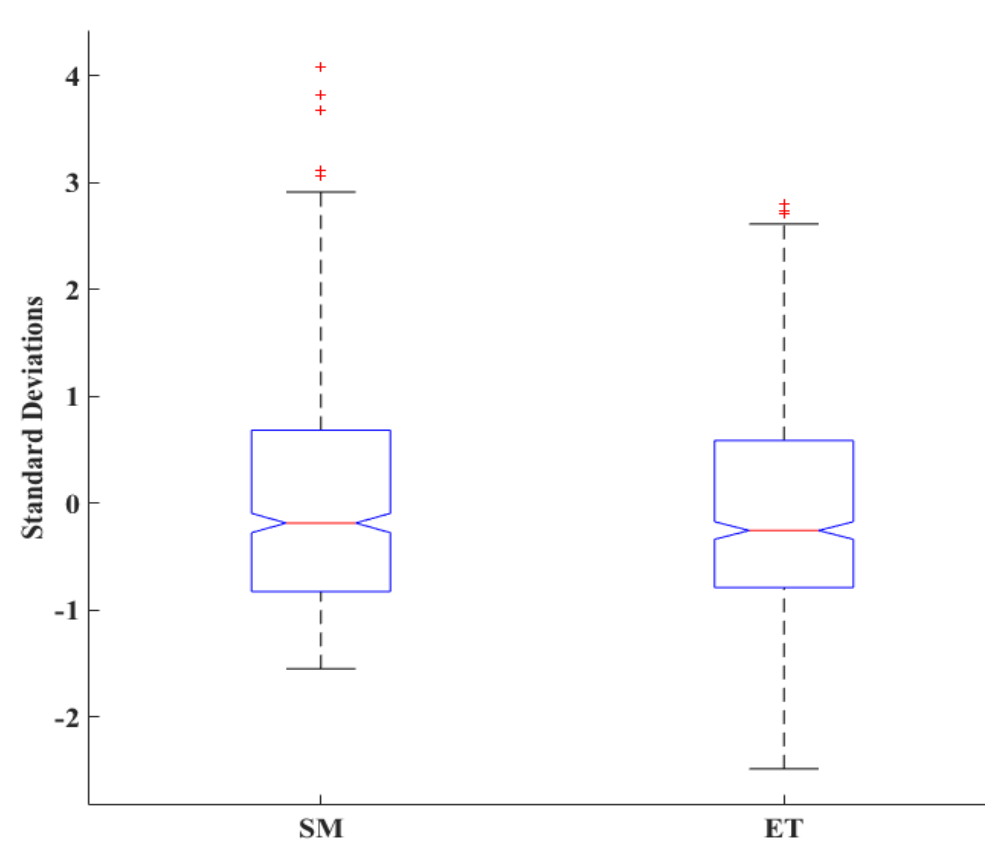

Figure 4. One-way ANOVA for standardized COSMOS soil moisture (SM) and PT-JPL-derived evapotranspiration (ET) within the inter-quartile range. This signifies that, during this period, the ET signature was de-coupled from the soil moisture signature. From Figure 2, it is seen that this period received frequent rainfall events, resulting in elevated soil moisture levels. Period \#4 corresponds with the Australian winter months of May,
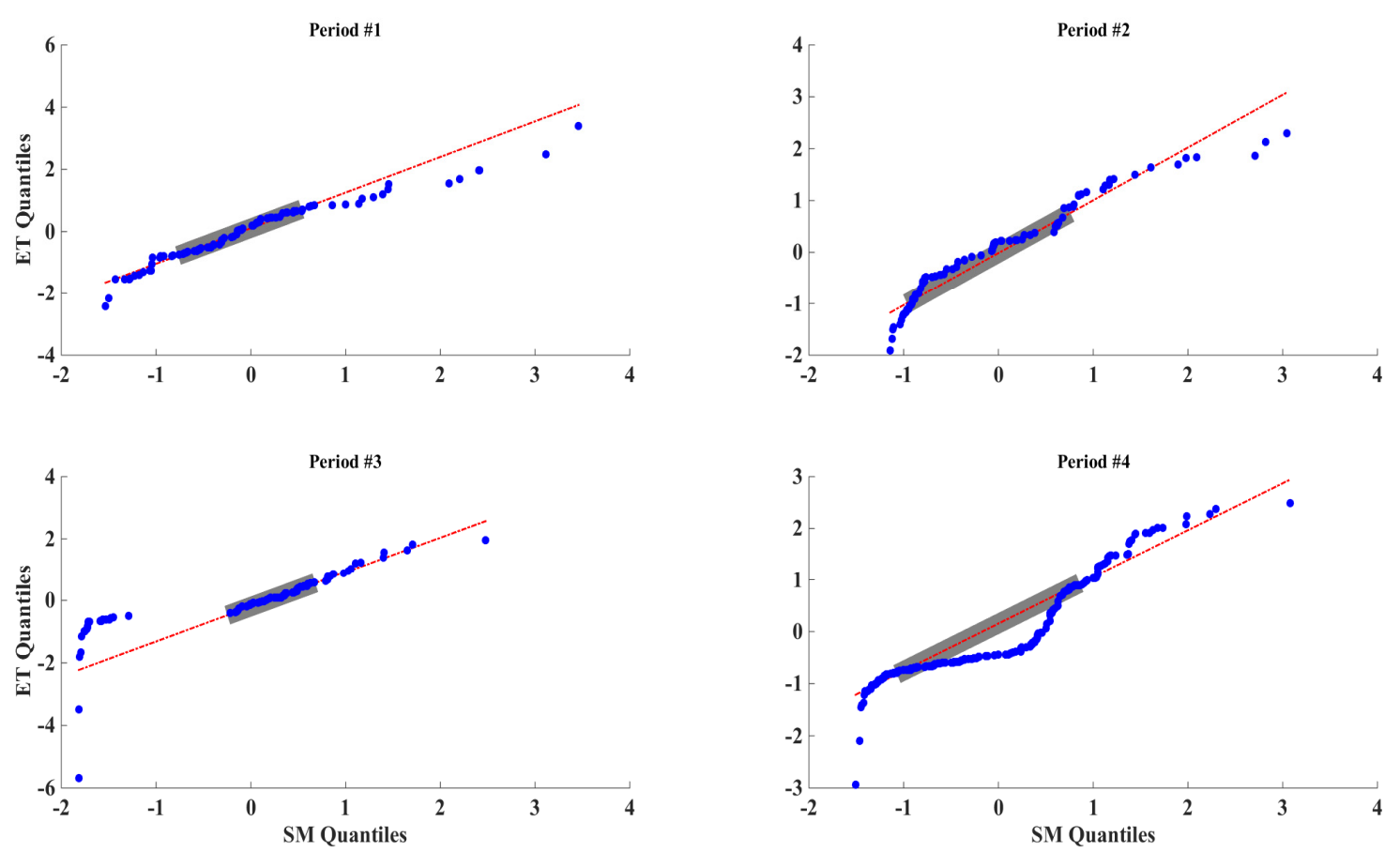

Figure 5. Q-Q plots of COSMOS soil moisture (SM) versus PT-JPL-derived evapotranspiration (ET) for the four analysis periods. 
June and July 2012. An increase in albedo and reduction in temperature, are also observed (Figure 2) in this period.

A comparison between the ANOVA boxplots of the PT-JPL-derived ET to that observed from the eddy covariance tower installed at the site during Period \#4 is shown in Figure 6. It is seen that the modeled (PTJPL) ET distribution is significantly different from that of the measured (EC-Tower). The measured ET distribution is also closer to the COSMOS soil moisture distribution, while that of the PT-JPL is skewed to the left. The PT-JPL method (Fisher et al., 2008) is primarily based on the available energy (Rn-G0) of the system as the prime determinant of ET. Soil moisture is indirectly accounted for by scaling the air humidity value. In situations similar to the Period \#4 of our study, it possible that the low temperatures and other hydro-meteorological factors cause a de-coupling of the soil moisture from the air humidity. In such situations, despite abundant soil moisture being present for evapotranspiration, the PT-JPL method would report lower values of ET as compared to those being measured from the EC tower. This could be a significant limitation of the PT-JPL method, requiring further study. It is possible that a Penman-Monteith type of model (Brutsaert, 2005; Ershadi et al., 2014) which specifically includes soil moisture conditions in the computation of the ET may be better suited under these conditions.

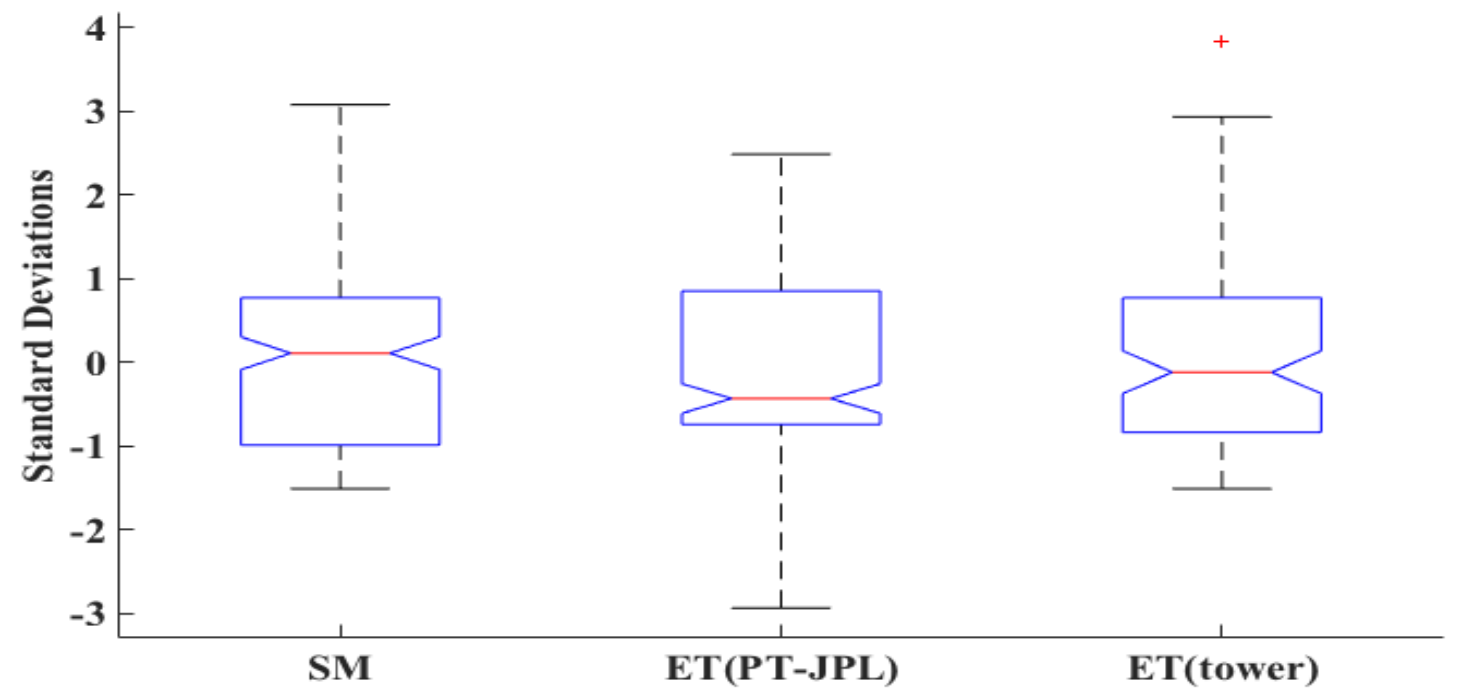

Figure 6. 1-way ANOVA for standardized COSMOS soil moisture (SM) and (a) PT-JPL-derived, and (b) eddy covariance tower measured evapotranspiration (ET) during Period \#4.

Other probable causes of errors could be uncertainties in the EC tower and COSMOS observations, and inaccurate MODIS observations due to the cloud cover, leading to further modeling inconsistencies. However, these uncertainties have not been explored in this study as they are considered generally constant over the study period and area.

\section{CONCLUSIONS}

Standardized ET product from the PT-JPL model using remotely sensed data was compared with standardized COSMOS soil moisture measurements. As hypothesized, the two quantities showed good correspondence with each other over the entire period of study, signifying that there is a strong relationship linking them. Similar correspondence was also observed during three of the four sub-periods analyzed. However, during periods of frequent precipitation and wintry conditions, the PT-JPL ET distribution deviated significantly from the COSMOS soil moisture distribution, and also from the ET measured from a tower onsite. Hence, while it has been shown that the COSMOS soil moisture and remotely-sensed ET are considerably linked, it may be necessary to further study the model for ET estimates best suited for certain conditions.

\section{ACKNOWLEDGEMENTS}

Research reported in this publication was supported by the King Abdullah University of Science and Technology (KAUST), Saudi Arabia. The COSMOS instrument was provided by the Commonwealth Scientific and Industry Research Organization. Instrumentation at the Baldry site were supported by the University of New South Wales and the National Center for Groundwater Research and Training. 


\section{REFERENCES}

Brutsaert, W., 2005. Hydrology: An Introduction. Cambridge University Press.

Desilets, D., Zreda, M. and Ferre, T.P.A., 2010. Nature's neutron probe: Land surface hydrology at an elusive scale with cosmic rays. Water Resources Research, 46(W11505).

Ershadi, A., McCabe, M., Evans, J., Chaney, N. and Wood, E., 2014. Multi-site evaluation of terrestrial evaporation models using FLUXNET data. Agricultural and Forest Meteorology, 187: 46-61.

Fisher, J.B., Tu, K.P. and Baldocchi, D.D., 2008. Global estimates of the land-atmosphere water flux based on monthly AVHRR and ISLSCP-II data, validated at 16 FLUXNET sites. Remote Sensing of Environment, 112(3): 901-919.

Hawdon, A., McJannet, D. and Wallace, J., 2014. Calibration and correction procedures for cosmic-ray neutron soil moisture probes located across Australia. Water Resources Research, 50(6): 5029-5043.

Jana, R.B. and Mohanty, B.P., 2012a. A comparative study of multiple approaches to soil hydraulic parameter scaling applied at the hillslope scale. Water Resour Res, 48.

Jana, R.B. and Mohanty, B.P., 2012b. On topographic controls of soil hydraulic parameter scaling at hillslope scales. Water Resources Research, 48(2).

Jana, R.B., Mohanty, B.P. and Sheng, Z., 2012. Upscaling Soil Hydraulic Parameters in the Picacho Mountain Region Using Bayesian Neural Networks. T Asabe, 55(2): 463-473.

Jana, R.B., Mohanty, B.P. and Springer, E.P., 2008. Multiscale Bayesian neural networks for soil water content estimation. Water Resour Res, 44(8).

Liu, Y.Y., de Jeu, R.A.M., McCabe, M.F., Evans, J.P. and van Dijk, A.I.J.M., 2011. Global long-term passive microwave satellite-based retrievals of vegetation optical depth. Geophys. Res. Lett., 38(18): L18402.

Liu, Y.Y. et al., 2012. Trend-preserving blending of passive and active microwave soil moisture retrievals. Remote Sensing of Environment, 123: 280-297.

Manfreda, S., McCabe, M.F., Fiorentino, M., Rodríguez-Iturbe, I. and Wood, E.F., 2007. Scaling characteristics of spatial patterns of soil moisture from distributed modelling. Advances in Water Resources, 30(10): 2145-2150.

McCabe, M.F., Gao, H. and Wood, E.F., 2005a. An evaluation of AMSR-E derived soil moisture retrievals using ground based, airborne and ancillary data during SMEX 02. J. Hydromet., 6(6): 864-877.

McCabe, M.F., Kalma, J.D. and Franks, S.W., 2005b. Spatial and temporal patterns of land surface fluxes from remotely sensed surface temperatures within an uncertainty modelling framework. Hydrology and Earth System Sciences, 9(5): 467-480.

McCabe, M.F., Wood, E.F. and Gao, H., 2005c. Initial soil moisture retrievals from AMSR-E: Multiscale comparison using in situ data and rainfall patterns overs Iowa. Geophysical Research Letters, 32(6): $1-4$.

Mintz, Y. and Walker, G., 1993. Global fields of soil moisture and land surface evapotranspiration derived from observed precipitation and surface air temperature. Journal of Applied Meteorology, 32(8): 1305-1334.

Seneviratne, S.I. et al., 2010. Investigating soil moisture-climate interactions in a changing climate: A review. Earth-Science Reviews, 99(3): 125-161.

Solano, R., Didan, K., Jacobson, A. and Huete, A., 2010. MODIS Vegetation Index User's Guide, Vegetation Index and Phenology Lab, The University of Arizona.

Stisen, S., McCabe, M.F., Refsgaard, J.C., Lerer, S. and Butts, M.B., 2011. Model parameter analysis using remotely sensed pattern information in a multi-constraint framework. Journal of Hydrology, 409(12): 337-349.

Su, H., Wood, E.F., McCabe, M.F. and Su, Z., 2007. Evaluation of remotely sensed evapotranspiration over the CEOP EOP-1 reference sites. Journal of the Meteorological Society of Japan, 85 A(SPEC. ISS.): 439-459.

Vinukollu, R.K., Wood, E.F., Ferguson, C.R. and Fisher, J.B., 2011. Global estimates of evapotranspiration for climate studies using multi-sensor remote sensing data: Evaluation of three process-based approaches. Remote Sensing of Environment, 115(3): 801-823.

Wan, Z., 2009. MODIS Land-Surface Temperature Algorithm Theoretical Basic Document (LST ATBD) Version 3.3, ICESS, University of California, Santa Barbara.

Wang, L. et al., 2012. Dryland ecohydrology and climate change: Critical issues and technical advances. Hydrology and Earth System Sciences, 16(8): 2585-2603.

Wetzel, P.J. and Chang, J.-T., 1987. Concerning the relationship between evapotranspiration and soil moisture. Journal of climate and applied meteorology, 26(1): 18-27.

Zreda, M. et al., 2012. COSMOS: the cosmic-ray soil moisture observing system. Hydrology and Earth System Sciences, 16(11): 4079-4099. 